\title{
Gestão da qualidade da informação no contexto das organizações: percepções a partir do experimento de análise da confiabilidade dos jornais eletrônicos
}

\section{José Osvaldo De Sordi}

Universidade Municipal de são caetano do sul (USCS; DOc. Pesquisador; Prof. Mestrado em Administraçao

Manuel Meireles

Faculdade Campo Limpo Paulista

Rogério Nahas Grijo

\section{Universidade Católica de Santos}

A presente pesquisa aborda a complexidade envolta na definição de atributos que permitam mensurar dimensões da qualidade da informação. Para isso, discute-se um experimento prático, que analisa em profundidade uma das dimensões da qualidade da informação: a confiabilidade. $A$ análise realizada abrange a versão eletrônica de cada um dos dez maiores jornais brasileiros impressos em circulação média diária. A experiência constatou ser crítico ao processo de análise da qualidade da informação o pleno discernimento dos atributos importantes de serem analisados, além dos aspectos importantes de serem observados para cada um dos atributos.

Palavras-chaves: Qualidade da Informação; Dimensões da Qualidade; Confiabilidade; Fonte da Informação; Jornal. 


\section{Management of quality of information in the context of the organizations: perceptions from the experiment of reliability analysis of the electronic newspapers}

The present research approaches the complexity involved in the definition of attributes that allow measuring the dimensions of information quality. For that, a practical experiment is discussed and it analyzes, in depth, one of the dimensions of the information quality: reliability. The analysis involves the electronic versions of the ten most important Brazilian printed daily medium circulation newspapers. The experience verified that the process of analysis of information quality is critical for the full discernment of the important attributes to be analyzed, in addition to the important aspects to be observed for each of the attributes.

Keywords: Information Quality; Quality Dimensions; Reliability; Information Source; Newspaper.

Recebido em 07.02.2008 Aceito em 18.06.2008

\section{Qualidade da informação}

A discussão sobre a qualidade da informação mostra ser esse um tema complexo e de muita controvérsia. No meio acadêmico, mais especificamente na área de ciência da informação, há o consenso de que se trata de um tema ainda incipiente, a ser desenvolvido.

A qualidade da informação constitui-se num conceito problemático. [...] não há consenso na literatura sobre definições teóricas e operacionais da qualidade da informação. Há uma alusão recorrente entre autores interessados no tema de que as definições de qualidade de informação são ambíguas, vagas ou subjetivas (PAIM, NEHMY e GUIMARÃES, 1996, p. 112).

Qualquer critério de avaliação da qualidade da informação é, por natureza, subjetivo. É praticamente impossível encontrar um critério de mensuração simples, preciso e satisfatório (SCHWUCHOW, 1990, p. 67). 
Do ponto de vista dos praticantes, ou seja, dos que atuam na gestão da informação no contexto das organizações, há, também, muitas dificuldades com relação à gestão da qualidade desse recurso. Oleto (2006) identificou que os usuários do ambiente informacional carecem de referenciais teóricos que tragam os conceitos de qualidade da informação para o cotidiano no ambiente das organizações. Os usuários das informações não possuem "a experiência de pensar a informação a partir de sua qualidade" (SCHWUCHOW, 1990, p. 61).

Apontadas algumas das dificuldades relacionadas ao tema qualidade da informação, tanto no contexto acadêmico quanto organizacional, cabe destacar a importância do recurso informação às modernas organizações, corroborando para o discernimento da importância de pesquisas relacionadas a esse tema. Desta forma, em termos de estratégia das organizações, é importante destacar que o recurso conhecimento fortemente dependente do recurso informação organizacional caracteriza um dos poucos recursos com alta capacidade de geração de valor e de difícil imitação pela concorrência. Trata-se de um dos poucos recursos organizacionais cuja gestão eficaz pode trazer bons resultados que perdurem a médio e longo prazo (RANFT e LORD, 2002; SVEIBY, 2001).

As pesquisas sobre qualidade da informação desenvolvem-se sob diferentes âmbitos ou dimensões de análise. Há muitas formas de categorização das dimensões da qualidade da informação. Garvin (1988), Salmela (1997), Tozer (1999) e Huang, Lee e Wang (1999) são alguns dos autores que esquematizaram diferentes conjuntos de dimensões. Huang, Lee e Wang (1999), por exemplo, desenvolveram uma lista de quinze dimensões para análise da informação, classificadas em quatro categorias:

(1) qualidade intrínseca: acurácia, objetividade, confiabilidade e reputação;

(2) qualidade de acessibilidade: acesso e segurança;

(3) qualidade contextual: relevância, valor-agregado, economia de tempo, completeza e quantidade de dados; e

(4) qualidade representacional: interpretabilidade, facilidade de uso, representação concisa e representação consistente.

As dimensões relacionadas à qualidade da informação não são facilmente identificadas, requerem análise e consenso entre geradores, leitores e demais interessados. Assim, tem-se que as dimensões da qualidade da informação são, em essência, informação a respeito de uma informação. A informação associada à própria entidade informação é denominada de metainformação (CARVALHO et al, 2004); aplicando-se o método dedutivo, tem-se que as dimensões da qualidade da informação são metainformações. 


\subsection{Sobre a dimensão confiabilidade da informação}

A confiabilidade tem sido objeto de estudo de diferentes áreas acadêmicas, entre elas a comunicação, a ciência da informação, a psicologia, a administração de marketing e as áreas interdisciplinares relacionadas à interação homem-máquina. Cada área aborda o tema e sua significância prática utilizando-se de fundamentos, métodos e objetivos distintos, o que resulta em visões conflitantes sobre a confiabilidade e seus efeitos (RIEH e DANIELSON, 2007).

A determinação da confiabilidade da informação torna-se um problema crescente à medida que mais e mais pessoas obtêm informações a partir da Internet, que continua a crescer rapidamente em termos de informações disponíveis. É importante destacar a diferença entre informação confiável e informação verdadeira. A informação confiável é aquela justificada, ou seja, aquela a que os usuários dão crédito, aquela em que se acredita, apesar de não haver um "atestado de veracidade" da mesma. A título de exemplo, as pessoas, até a metade do século XIX, acreditavam nos princípios do mecanicismo Newtoniano, por que era o melhor método e única evidência da época com relação ao tema. Desta forma, temos que confiabilidade não é sinônimo de informação verídica (VEDDER e WACHBROIT, 2003). A veracidade caracteriza outra dimensão da qualidade da informação, que não compõem o objeto da presente pesquisa.

A confiabilidade da informação está fortemente atrelada à percepção do leitor quanto à autoridade e confiabilidade da fonte (HARRIS, 1997). Corroborando com este raciocínio, Davenport (2002) salienta que, entre os atributos que asseguram o envolvimento do usuário com a informação, estão: o preparo ou a capacitação do emissor percebida pelo receptor, o poder e apelo pessoal do emissor e a familiaridade do receptor com relação ao emissor. Segundo Paim, Nehmy e Guimarães (1996), a confiabilidade relaciona-se com a idéia de autoridade cognitiva: prestígio, respeito, reputação da fonte, autor ou instituição. A confiabilidade assemelha-se a uma espécie de fé (GIDDENS, 1991).

Embora o critério mais citado para análise da confiabilidade da informação seja a credibilidade do autor, há outro critério tão importante quanto: a credibilidade do conteúdo. Este último critério refere-se a evidências a favor do conteúdo da informação, obtidas por diferentes meios, desde as que empregam o julgamento pelo senso-comum até as fundamentadas em sofisticadas técnicas de confirmação da metodologia da pesquisa científica, incluindo aplicação de modelos estatísticos e probabilísticos, projetos experimentais, entre outros recursos (VEDDER e WACHBROIT, 2003). Assim, tem-se que a confiabilidade da informação é mensurada a partir da análise das variáveis: credibilidade da fonte e credibilidade do conteúdo. Estas duas variáveis influenciam-se mutuamente; ou seja, fontes confiáveis são entendidas como desenvolvedoras de conteúdo confiáveis, e conteúdos confiáveis são 
entendidos como originados por fontes confiáveis (SLATER e ROUNER, 1996).

Os métodos para atribuição de níveis de credibilidade da fonte, normalmente empregados pelas pessoas, podem ser classificados em: credibilidade presumida, obtida a partir de hipóteses elaboradas pelo observador com relação à fonte, por exemplo, a partir de estereótipos; credibilidade reputada, a partir da apresentação de títulos e designações apresentados pela fonte; credibilidade superficial, a partir da imagem e apresentação da fonte; e credibilidade experimentada, com base no tempo de relacionamento do observador com a fonte (TSENG e FOGG; 1999). Estes métodos não científicos, ou "de uso cotidiano", caracterizamse pelo pouco rigor e pela imprecisão da informação gerada.

\section{Sobre a pesquisa}

A presente pesquisa tem como objeto de estudo a dimensão confiabilidade da fonte de informação. O objetivo da pesquisa é refletir sobre a complexidade envolta na definição de atributos que permitam mensurar dimensões de qualidade da informação com mais rigor, formalismo e integridade que as práticas "de uso cotidiano". A fim de aumentar os subsídios para a exposição da complexidade relacionada ao tema, decidiu-se realizar a análise da confiabilidade de um conjunto de fontes afins, ou seja, de um mesmo segmento de negócio. Para melhor entendimento de todos os interessados na pesquisa, optou-se por selecionar um conjunto de amplo domínio do grande público: a mídia impressa de notícias (jornais) brasileira, mais especificamente, a versão eletrônica desses jornais.

O aspecto central da pesquisa não é a apuração em si, dos aspectos de confiabilidade da fonte, atendidos ou não pelos principais jornais brasileiros, mas sim a reflexão de atributos, e de seus aspectos passíveis de serem mensurados, que auxiliem a entender e delinear aspectos objetivos relacionados às dimensões da qualidade da informação, exemplificada nesse estudo pela discussão da dimensão confiabilidade. A análise dos maiores jornais brasileiros tem dois objetivos: a) auxiliar na reflexão sobre os atributos que corroboram com o discernimento da dimensão confiabilidade da fonte; b) auxiliar a demonstrar a importância dessa dimensão para a gestão da informação no contexto organizacional.

Ao longo dos últimos anos, fortaleceu-se a percepção dos pesquisadores de que os gestores organizacionais deveriam ater-se mais ao recurso "informação", em detrimento dos esforços e da dedicação excessiva junto aos novos e atrativos recursos da "tecnologia da informação". A postura gerencial de investir intensamente em recursos de tecnologia da informação, considerando isso suficiente para solucionar os problemas de informação nas organizações, foi denominado por Davenport (2002) como "utopia tecnocrática". Esse cenário é importante para a compreensão da justificativa da presente pesquisa, considerando que a gestão da qualidade da informação representa uma atividade eficaz 
e diretamente associada à gestão do recurso informação. Um dos principais desafios dos gestores da informação contemporâneos é auxiliar seus usuários a distinguirem a informação de qualidade, dentre o crescente conjunto de informação disponível. Para isso, o gestor deve desenvolver a cultura e a prática de análise da qualidade da informação junto à sua comunidade de usuários. O discernimento sobre o que é importante de ser aferido para averiguar a qualidade da informação dimensões de análise - e como mensurar, ou seja, os atributos associados a cada dimensão, devem ser parte integrante da cultura coletiva com relação ao recurso informação.

Para a descrição dos métodos utilizados, é importante destacar que a pesquisa ocorreu em três fases: a primeira, voltada à definição dos atributos que auxiliam a mensurar a dimensão confiabilidade da fonte; a segunda, voltada à experimentação prática dos atributos definidos para análise de confiabilidade das versões eletrônicas das principais mídias impressas brasileiras; a terceira, direcionada à reflexão e interpretação da experiência.

\subsection{Primeira fase da pesquisa: reflexão sobre atributos para análise da confiabilidade}

$\mathrm{Na}$ fase de estruturação da pesquisa, realizou-se uma pesquisa exploratória inicial, objetivando identificar pesquisas realizadas sobre análise da confiabilidade de fontes. Dessa pesquisa inicial, os pesquisadores tomaram ciência de estudos realizados pelo International Center for Media and the Public Agenda (ICMPA) da Universidade de Maryland, que analisou a confiabilidade das principais mídias noticiosas da Internet. O ICMPA divulgou, em junho de 2007, o relatório "Openness \& Accountability: A Study of Transparency in Global Media Outlets". Este relatório analisa o nível de transparência de 25 importantes sítios (web sites) de notícias, pertencentes a importantes empresas de mídia dos Estados Unidos, Inglaterra e Oriente Médio (INTERNATIONAL CENTER FOR MEDIA AND THE PUBLIC AGENDA, 2007). Esses sítios de notícias serão denominados ao longo desse texto de jornais eletrônicos.

O grupo de pesquisa do ICMPA definiu a variável transparência dos jornais eletrônicos como fator importante para a obtenção da confiabilidade dessas mídias junto ao público leitor: "transparência remete à responsabilidade e essa, por conseguinte, remete à confiabilidade" (INTERNATIONAL..., 2007). Para averiguação do nível de transparência dos jornais eletrônicos, os pesquisadores do ICMPA identificaram cinco atributos importantes de serem analisados: correção de erros; propriedade; política de emprego; política editorial e interatividade. Para cada um desses cinco atributos, definiu-se aspectos a analisar, o que permitiu classificar os jornais eletrônicos perante uma escala de cinco níveis de transparência, variando de transparência inexistente (nota zero) a transparência total (nota quatro). 
Os relatórios publicados pelo ICMPA não descrevem os critérios utilizados para a mensuração de cada um dos cinco atributos de transparência da fonte analisados, apenas as avaliações e comentários dessas, para cada um dos 25 jornais eletrônicos analisados. A presente pesquisa teve que realizar uma investigação dos critérios utilizados a partir das avaliações e comentários publicados a respeito de cada jornal eletrônico, perante cada um dos cinco atributos analisados. Portanto, nessa primeira fase da pesquisa, partiu-se de constatações particulares de relatos da pesquisa do ICMPA, para desenvolver generalizações; ou seja, utilizou-se o método de pesquisa indutiva (LAKATOS e MARCONI, 1993), tendo a pesquisa documental (GIL, 1991) como principal procedimento técnico empregado.

\subsection{Segunda fase da pesquisa: análise de confiabilidade das mídias brasileiras}

Sendo o universo da pesquisa os jornais eletrônicos pertencentes às mídias jornalísticas impressas brasileiras, para delimitar a amostra optouse por pesquisar a confiabilidade dos dez maiores jornais brasileiros em termos de circulação média diária, segundo apurado pela Associação Nacional de Jornais (ANJ). A ANJ é uma associação com fins nãoeconômicos, composta por 134 sociedades jornalísticas, em âmbito Nacional, que elabora anualmente o ranking dos maiores jornais em termos de circulação, ranking este aferido pelo Instituto Verificador de Circulação (IVC). Assim, a amostra da presente pesquisa é composta pelos jornais: "Folha de São Paulo", "O Globo", "Extra", "O Estado de São Paulo", "Zero Hora", "Correio do Povo", "Diário Gaúcho", "Super Notícia", "Meia Hora" e "O Dia" (ASSOCIAÇÃO NACIONAL DE JORNAIS, 2007).

Nesta segunda fase da pesquisa, utilizou-se o levantamento como procedimento técnico (GIL, 1991), considerando que os pesquisadores acessaram e analisaram os jornais eletrônicos dos dez maiores jornais brasileiros em circulação média diária, em busca de informações diretamente associadas aos aspectos centrais relacionados aos cinco atributos definidos na primeira fase da pesquisa.

\subsection{Terceira fase da pesquisa: reflexões sobre o experimento realizado}

Após o término das duas primeiras fases da pesquisa - (a) compreensão dos critérios adotados pelo ICMPA para avaliar a confiabilidade das principais mídias internacionais e (b) replicação da pesquisa para o contexto brasileiro -, os pesquisadores se reuniram, a fim de analisar os fatos ocorridos e os resultados alcançados. Nessa fase, os pesquisadores refletiram sobre a experiência da análise da dimensão confiabilidade da fonte para o contexto das versões eletrônicas dos maiores jornais brasileiros em circulação média diária. Os pesquisadores se submeteram a uma experiência real, similar às enfrentadas por 
gestores de informação organizacionais, que analisam fontes de informações a fim de definir sua utilização como insumo válido aos processos de tomada decisão.

Nessa última fase, os pesquisadores apresentam uma descrição direta da experiência realizada, que é entendida, compreendida e interpretada segundo a experiência deles, atuando como gestores da informação no processo de mensuração da dimensão, segundo o contexto e a lógica estabelecida para o experimento. As realidades analisadas não são únicas, podendo existir tantas quantas forem as interpretações e comunicações realizadas. Portanto, nesta fase da pesquisa se utilizou o método de pesquisa fenomenológico (TRIVIÑOS, 1992).

Nas próximas três seções são apresentados os resultados das três fases da pesquisa, respectivamente: (seção 3) os critérios para avaliação da dimensão confiabilidade para mídias de notícias na Internet, induzidos a partir das pesquisas do ICMPA; (seção 4) a apuração da análise da dimensão confiabilidade para as principais mídias de notícias brasileiras; e (seção 5) reflexões sobre o uso de dimensões para análise da qualidade da informação.

\section{Atributos para análise da confiabilidade de mídias impressas}

As pesquisas desenvolvidas pelo grupo de pesquisa ICMPA da Universidade de Maryland, a respeito da confiabilidade das principais mídias jornalísticas na Internet, se pautaram em cinco aspectos diretamente associados à transparência dessas entidades junto aos leitores: correção de erros; propriedade; política de emprego; política editorial e interatividade. Para cada atributo, definiram-se características a serem analisadas e classificadas em um escala de cinco níveis: transparência inexistente (0), pouca transparência (1), média transparência (2), boa transparência (3), e transparência total (4).

O atributo correção de erros objetiva identificar se a mídia assume publicamente seus erros. A capacidade de assumir seus próprios erros dá confiabilidade à mídia jornalística; indica que ela não defenderá informações não verídicas, ou seja, se pautará pela verdade. Trata-se de um atributo essencial para uma empresa de mídia que tem como serviço principal a distribuição da informação e a análise de fatos.

$\mathrm{Na}$ pesquisa realizada pelo ICMPA, as mídias que obtiveram nota máxima - transparência total - nesse atributo foram: The Guardian, New York Times, Cristian Science Monitor, NPR, LA Times, Washington Post, MSNBC e Wall Street Journal. Como justificativas para obtenção da nota máxima (nota 4), identificaram-se: correções e esclarecimentos facilmente encontrados em página de errata, atualizada diariamente; os textos de correção estão associados ao texto original via link, estando todas essas informações centralizadas em uma página do jornal eletrônico, facilmente acessada. As mídias identificadas com boa transparência (nota 3) foram: CBS News, Financial Times, Miami Herald e 
New'sweek. Observou-se apenas uma diferença dessas para o grupo com nota máxima: a página de errata não é facilmente encontrada, são necessários mais de dois cliques de mouse a partir da página central. Média transparência (nota 2) foi apurada apenas para uma mídia: NBC News. A justificativa estava na inexistência de uma página no jornal eletrônico da mídia que centralizasse as correções e explicações, ficando essas fragmentadas e distribuídas nas páginas onde ocorreram os erros originários. Isso dificulta ao visitante descobrir onde o veiculo errou e a freqüência desses erros. Pouca transparência (nota 1) não foi atribuída a nenhuma das mídias analisadas. Transparência inexistente (nota 0 ) foi atribuída para diversas mídias: PRI, Int'l Herald Tribune, USA Today, ABC News, Fox News, The Econimist, Daily Telegraph, CNN, Al Jazeera English, ITN, Time e Sky News. Para essas mídias, observou-se a inexistência da publicação de correções, seja em página específica ou distribuída pelas diversas páginas de notícias.

O atributo propriedade objetiva identificar se a mídia declara aos leitores quem são seus proprietários e controladores. A declaração dos proprietários é vital para que o leitor possa analisar o nível de independência ou viés causado por esses, em termos de postura da mídia com relação a notícias e análises associadas a temas de interesse direto dos proprietários.

$\mathrm{Na}$ pesquisa realizada pelo ICMPA, as mídias que obtiveram nota máxima - transparência total - nesse atributo foram: The Guardian, New York Times, BBC News, Cristian Science Monitor, NPR, Miami Herald, PRI, MSNBC, Wall Street Journal, Int'l Herald Tribune, ABC News, Fox News, The Economist e ITN. Como justificativas para obtenção da nota máxima (nota 4) identificaram-se: a informação sobre os proprietários da mídia é apresentada de forma clara, sendo facilmente encontrada, no máximo com dois cliques de mouse a partir da tela principal do jornal eletrônico; há também declarações sobre a missão, visão e valores da organização. As mídias identificadas com boa transparência (nota 3) foram: Financial Times, LA Times, Washington Post, Newsweek, Daily Telegraph e CNN. Observou-se apenas uma diferença dessas para o grupo com nota máxima: informações disponíveis, porém com dificuldade para acesso, ou seja, mais de dois cliques a partir da página principal da mídia. Média transparência (nota 2) foi apurada para: CBS News e Al Jazeerah English. Nessas mídias, encontra-se facilmente a declaração de seus proprietários, porém não de forma clara; o caso típico ocorre quando uma companhia é proprietária de outra, que tem participação em outra, caracterizando um imbróglio societário que torna dificultosa a identificação dos proprietários. Pouca transparência (nota 1) foi atribuída às mídias Time e SkyNews. Para essas, observou-se que, além de não ficar claro quais são os proprietários de fato, adiciona-se o problema da dificuldade de acesso à informação. Transparência inexistente (nota 0) não foi atribuída para nenhuma das mídias analisadas.

O atributo política de emprego objetiva identificar se a mídia tem discernimento e declara os procedimentos internos para a resolução de 
possíveis conflitos de interesse. Nessa área, são muitos os conflitos possíveis, que devem estar muito bem declarados, não apenas para o público interno, mas também para o externo. Por exemplo, qual a postura esperada do editor na urgência de definir pela publicação ou não de um "furo de reportagem", de contexto negativo, associado ao maior anunciante da mídia? Questões como essas devem estar declaradas para que o público leitor possa ter discernimento do nível de independência da mídia.

$\mathrm{Na}$ pesquisa realizada pelo ICMPA, as mídias que obtiveram nota máxima - transparência total - nesse atributo foram: The Guardian, New York Times, BBC News, CBS News e NPR. Como justificativas para obtenção da nota máxima (nota 4) identificaram-se: a presença de um Código de Ética e Conflito de informações bem definido e disponível para todos os interessados. No caso da CBS News, há inclusive um link, denominado "Public Eye", onde estão disponibilizados os vídeos das reuniões editoriais e reuniões em que participam os tomadores de decisão editoriais. Apenas a PRI foi identificada como possuidora de boa transparência (nota 3) para esse atributo; apesar de existir um Código de Ética, a declaração da política de conflito de interesses é vaga. Média transparência (nota 2) foi apurada para: Financial Times e LA Times. No caso do Financial Times, não há informação sobre qual a postura adotada para a resolução de conflitos de interesse, mas há um Código de Ética disponível sob a denominação "Código de Práticas". Com relação ao LA Times, em seu jornal eletrônico não há publicação relativa à política de resolução de conflitos de interesse, porém, apresenta um link para o sítio da ASNE (Sociedade Americana de Editores de Jornais), que apresenta um bom Código de Ética. Pouca transparência (nota 1) foi atribuída às mídias: Cristian Science Monitor, Miami Herald, Washington Post, USA Today e Daily Telegraph. Nessas observou-se que, embora haja um Código de Ética, este é vago, desatualizado e não apresenta qualquer referência a conflitos de interesse. Transparência inexistente (nota 0) foi atribuída para diversas mídias: MSNBC, Wall Street Journal, Int'l Herald Tribune, Newsweek, ABC News, Fox News, The Econimist, CNN, Al Jazeera English, ITN, Time e Sky News. Essas organizações não apresentam nenhuma declaração relacionada ao Código de Ética.

O atributo política editorial objetiva identificar se a mídia tem um conjunto de normas e princípios bem definidos que orientem seus colaboradores sobre o que deve ser editado, como editar e para quem devem ser editadas as publicações (RODRIGUES, 1986; ROSINHA, 1989).

$\mathrm{Na}$ pesquisa realizada pelo ICMPA, as mídias que obtiveram nota máxima - transparência total - nesse atributo foram: The Guardian, $B B C$ News, CBS News e Cristian Science Monitor. Como justificativas para obtenção da nota máxima (nota 4) identificaram-se: a explicitação da política de valores organizacionais, explicando como os valores organizacionais afetam o que se publica. Essa política é disponibilizada aos leitores em uma página específica do jornal eletrônico, sendo de fácil acesso, não mais que dois cliques a partir da página principal. As mídias 
identificadas com boa transparência (nota 3) foram: NPR e PRI. Nessas, os valores da organização encontram-se explicitamente declarados, mas com partes do texto distribuídas em diversas localidades do jornal eletrônico. Média transparência (nota 2) foi apurada para: New York Times, Financial Times e Int'l Herald Tribune. Apresentam as informações centralizadas, porém o conteúdo apresenta pouco detalhamento (aborda superficialmente). Pouca transparência (nota 1) foi atribuída às mídias: $L A$ Times, Miami Herald, Washington Post, The Economist e Al Jazeerah English. Para essas, a política editorial, além de não estar centralizada em apenas um local, sua redação é vaga e pouco precisa. Transparência inexistente (nota 0) foi atribuída às mídias: MSNBC, Wall Street Journal, Newsweek, ABC News, USA Today, Fox News, Daily Telegraph, CNN, ITN, Time e Sky News. Essas mídias não apresentam política editorial.

$\mathrm{O}$ atributo interatividade objetiva identificar se a mídia tem um bom canal estabelecido para a comunicação com seus leitores. Essa abertura para ouvir seus leitores demonstra maturidade da organização em termos de capacidade de auto-aprendizagem, em termos de melhor orientar-se para os anseios e necessidades de seu público-alvo.

$\mathrm{Na}$ pesquisa realizada pelo ICMPA, as mídias que obtiveram nota máxima - transparência total - nesse atributo foram: Financial Times e Miami Herald. Como justificativas para obtenção da nota máxima (nota 4) identificaram-se: há a seção "Cartas ao Editor" que permite que cada uma delas seja lida ao acionar o respectivo link; declara-se o endereço eletrônico (e-mail) de cada colunista e repórter da mídia; há disponibilidade de blogs e sessões onde os usuários do portal da mídia são estimulados a interagirem entre si, inclusive comentando cada notícia e coluna publicada. As mídias identificadas com boa transparência (nota 3) foram: The Guardian, New York Times, CBS News, Christian Science Monitor, LA Times, Washington Post, Int'l Herald Tribune, USA Today. A diferença dessas mídias para as que receberam a avaliação máxima é a ausência do estímulo à participação dos leitores, a discutir e comentar as notícias. Média transparência (nota 2) foi apurada para: BBC News, MSNBC, Wall Street Journal, Newsweek, ABC News, Fox News, Daily Telegraph, CNN e Time. Nessas mídias há alguns recursos de interatividade, porém restritos à comunidade de assinantes; não há facilidade de visualização de comentários de outros leitores e não é possível contatar repórteres de forma direta. Pouca transparência (nota 1) foi atribuída às mídias: NPR, PRI, The Economist, Al Jazeera English e Sky News. Nessas mídias há apenas o link de envio de cartas ao editor. Transparência inexistente (nota 0 ) foi atribuída apenas à mídia ITN, que não provê nenhuma facilidade de interatividade com os leitores.

Da pesquisa indutiva realizada a partir do relatório e dos documentos publicados pelo grupo de pesquisa do ICMPA, identificaramse cinco atributos a serem pesquisados, e os aspectos ou características centrais destes atributos a serem investigadas no jornal eletrônico das mídias brasileiras. No QUAD. 1 há a descrição: dos atributos pesquisados, da pergunta de referência para análise desses, bem como dos aspectos ou 


\title{
características consideradas para classificação da mídia em relação ao nível de transparência para o atributo em questão.
}

\section{QUADRO 1 - Atributos e seus aspectos considerados para análise de confiabilidade das mídias de notícias brasileiras}

\begin{abstract}
Atributo: CORREÇÃO DE ERROS
Pergunta de referência: Existe disposição da mídia em reconhecer e retificar publicamente seus erros?

Aspectos considerados para classificação:

Transparência inexistente (0): não há publicação de textos referentes a tratamento de erros:

Pouca transparência (1): textos de correções são encontrados, porém de forma parcial, seja apenas para uma ou algumas sessões específicas de temas ou assuntos tratados pela mídia, ou apenas para um período de tempo, para publicações mais antigas; ou seja, há indícios de que não se trata de uma prática vigente e organizacional;

Média transparência (2): textos de correções existem, porém encontram-se fragmentados e distribuídos nas próprias páginas onde ocorreram os erros;

Boa transparência (3): correções e esclarecimentos sobre publicações atuais são facilmente encontrados, centralizados na página de erratas, essas estão associadas ao texto original onde ocorreu o erro por intermédio de um link, porém não possuem fácil acesso, requerem mais de dois cliques de mouse a partir da página principal da mídia;

Transparência total (4): correções e esclarecimentos sobre publicações atuais são facilmente encontrados (até dois cliques a partir da página central), centralizados em página de errata e vinculados ao texto original onde ocorreu o erro por intermédio de link.
\end{abstract}

\section{Atributo: PROPRIEDADE}

Pergunta de referência: A mídia informa quem são seus proprietários?

Aspectos considerados para classificação:

Transparência inexistente (0): informação sobre os proprietários da mídia não disponível;

Pouca transparência (1): informação disponível, porém de difícil acesso (requer mais de dois cliques de mouse a partir da tela principal do jornal eletrônico) e pouco informativa ou significativa; por exemplo, descreve imbróglio societário;

Média transparência (2): informação facilmente encontrada (acessada com até dois cliques de mouse a partir da tela principal do jornal eletrônico), porém pouco informativa ou significativa; por exemplo, descreve imbróglio societário;

Boa transparência (3): informação apresentada de forma clara, porém de difícil acesso (requer mais de dois cliques de mouse a partir da tela principal do jornal eletrônico);

Transparência total (4): informação apresentada de forma clara e facilmente encontrada (acessada com até dois cliques de mouse a partir da tela principal do jornal eletrônico).

\section{Atributo: POLÍTICA DE EMPREGO}

Pergunta de referência: Os leitores são informados sobre como a empresa direciona seus colaboradores no tratamento de conflitos de interesses?

Aspectos considerados para classificação:

Transparência inexistente (0): não há publicação de textos ou documentos referentes ao Código de Ética e Conflitos de Interesses a serem seguidos pelos colaboradores;

Pouca transparência (1): há um Código de Ética, porém esse é vago, desatualizado e não faz menção aos possíveis conflitos de interesse;

Média transparência (2): há um Código de Ética disponível, porém não há menção aos possíveis conflitos de interesse;

Boa transparência (3): há um Código de Ética disponível, porém o tratamento dado à política de Conflito de Interesse é vaga;

Transparência total (4): os documentos Código de Ética e Conflitos de Interesse são claros, objetivos e facilmente encontrados pelos leitores (acessados com até dois cliques de mouse a partir da tela principal do jornal eletrônico).

\section{Atributo: POLÍTICA EDITORIAL}

Pergunta de referência: Os leitores são informados sobre os valores organizacionais que orientam o trabalho dos seus colaboradores? Aspectos considerados para classificação:

Transparência inexistente (0): não há publicação de textos referentes à política editorial;

Pouca transparência (1): há política editorial, seus textos estão subdivididos em partes localizadas em diferentes páginas do jornal eletrônico, sendo sua redação vaga;

Média transparência (2): a política editorial encontra-se centralizada, porém a sua redação é vaga;

Boa transparência (3): os textos são claros, objetivos, porém de difícil acesso; encontram-se, por exemplo, subdivididos em partes localizadas em diferentes páginas do jornal;

Transparência total (4): os textos referentes à política editorial estão centralizados em uma página, são claros, objetivos e de fácil acesso aos leitores.

\section{Atributo: INTERATIVIDADE}

Pergunta de referência: Os leitores são incentivados a expressarem seus comentários e críticas a respeito das publicações da mídia?

Aspectos considerados para classificação:

Transparência inexistente (0): não provê facilidades para interação dos leitores;

Pouca transparência (1): provê apenas a facilidade de carta ao editor;

Média transparência (2): apresenta diversas facilidades para interação de seus leitores (seção carta ao editor, blogs, divulgação de e-mail dos colaboradores, entre outras), porém disponíveis apenas aos leitores assinantes;

Boa transparência (3): apresenta diversas facilidades para interação de todos seus leitores (seção carta ao editor, comente a notícia, dando visibilidade da opinião de outros leitores; blogs; divulgação de e-mail dos colaboradores, entre outras), sejam eles assinantes ou não;

Transparência total (4): similar ao item anterior, porém acrescido de forte estímulo à interação dos usuários como, por exemplo, o fornecimento grátis de serviços (alertas sobre notícias de interesse, resumo de notícias por e-mail) ou sorteio de prêmios entre os que interagem (descontos na assinatura do jornal).

\section{Fonte: Elaborado pelos autores.}


A confiabilidade dos jornais eletrônicos brasileiros foi mensurada a partir da análise de cinco atributos (correção de erros, propriedade, política de emprego, política editorial e interatividade) segundo os aspectos descritos no QUAD. 1. Para cada atributo obteve-se uma avaliação numérica variando entre 0 (zero) e 4 (quatro), relativa aos seguintes níveis de transparência: transparência inexistente, nota 0 (zero); pouca transparência, nota 1 (um); média transparência, nota 2 (dois); boa transparência, nota 3 (três); e transparência total, nota 4 (quatro). A intensidade média de transparência de cada jornal eletrônico foi obtida a partir da média aritmética das notas apuradas para os cinco atributos. As avaliações dos cinco atributos e a média final de transparência de cada um dos nove jornais eletrônicos analisados estão descritas na TAB. 1. Nessa tabela, a apresentação se dá em ordem decrescente de transparência dos nove jornais eletrônicos analisados. Nos parágrafos a seguir estão descritos aspectos importantes identificados durante as análises dos cinco atributos para cada um dos nove jornais eletrônicos analisados.

\subsection{Análise dos atributos do jornal eletrônico da "Folha de São Paulo"}

Para o atributo correção de erros, encontrou-se na parte inferior da página principal o link "Erramos". Nessa seção, aparecem organizados, em ordem cronológica, os textos relativos às correções de erros do jornal eletrônico. As correções estão associadas por link à matéria original onde ocorreu o erro. Desta forma, segundo os aspectos analisados para o atributo e as classificações de transparência possíveis, descritas no Quadro 1, atribuiu-se a classificação "transparência total", ou seja, nota 4 (quatro).

Quanto ao atributo propriedade, acessou-se a partir da página principal o link "Grupo Folha", e, a partir dessa, acessou-se, sequencialmente, os links "Conheça a Folha" e "História da Folha". Nessa página há a informação de que o empresário Octavio Frias de Oliveira possui o controle acionário da companhia. Por requerer mais de dois cliques de mouse para acesso à informação, segundo as regras definidas para avaliação do atributo, descritas em QUAD.1, atribui-se a classificação "boa transparência", ou seja, nota 3 (três).

Com relação ao atributo política de emprego não se observou qualquer referencia aos assuntos Código de Ética e Conflitos de Interesses, portanto, atribuiu-se "transparência inexistente", nota 0 (zero).

Para o atributo política editorial, partindo da página principal, acessa-se o link "Grupo Folha", na seqüência os links: "Conheça a Folha" e "Linha Editorial". A Folha de São Paulo declara resumidamente: "estabelece como premissa de sua linha editorial a busca por um jornalismo crítico, apartidário e pluralista". Segundo as regras de 
avaliação de transparência, declaradas em QUAD. 1, atribui-se, "média transparência", ou seja, nota 2 (dois).

TABELA 1 - Nível de transparência dos jornais eletrônicos analisados

\begin{tabular}{|c|c|c|c|c|c|c|}
\hline Jornal & $\begin{array}{c}\text { Correção de } \\
\text { Erros }\end{array}$ & Propriedade & $\begin{array}{c}\text { Politica de } \\
\text { Emprego }\end{array}$ & $\begin{array}{l}\text { Politica } \\
\text { Editorial }\end{array}$ & Interatividade & $\begin{array}{c}\text { Nível }^{*} \text { de } \\
\text { Transparência }\end{array}$ \\
\hline Folha de São Paulo & 4 & 3 & 0 & 2 & 3 & 2,4 \\
\hline O Globo & 2 & 4 & 0 & 0 & 3 & 1,8 \\
\hline O Estado de São Paulo & 2 & 3 & 0 & 1 & 3 & 1,8 \\
\hline Extra & 0 & 4 & 0 & 0 & 1 & 1 \\
\hline Zero Hora & 0 & 2 & 0 & 0 & 1 & 0,6 \\
\hline Diário Gaúcho & 0 & 2 & 0 & 0 & 1 & 0,6 \\
\hline Correio do Povo & 0 & 0 & 0 & 0 & 1 & 0,2 \\
\hline Super Notícia & 0 & 0 & 0 & 0 & 1 & 0,2 \\
\hline O Dia & 0 & 0 & 0 & 0 & 0 & $\mathbf{0}$ \\
\hline * Nível de transparência & $0=$ inexis & $1=p$ & $2=m$ & $3=b$ & $4=$ total & \\
\hline
\end{tabular}

FONTE: Elaborado pelos autores.

No que tange à interatividade, o jornal disponibiliza aos usuários, tanto para assinantes quanto para não-assinantes, o sistema de comentário de notícias mediante cadastro do usuário. Esse ambiente permite aos usuários avaliarem comentários postados por outros usuários. O jornal também divulga na página os endereços eletrônicos (e-mails) de repórteres e profissionais da redação; há também um canal direto de relacionamento com o ombudsman. Apesar das diversas facilidades disponíveis para interação, não se observou incentivos à interação dos usuários. Dessa forma, atribui-se à interatividade do jornal a classificação "boa transparência", ou seja, nota 3 (três).

\subsection{Análise dos atributos do jornal eletrônico de "O Globo"}

A versão eletrônica do jornal "O Globo" não disponibiliza informações referentes aos atributos: política de emprego e política editorial. Assim, atribuiu-se a eles a classificação "transparência inexistente", ou seja, nota 0 (zero).

Para o atributo correção de erros, não há uma página onde se centralizem as correções; porém, em cada matéria, existe a opção do leitor, mediante cadastro prévio, enviar um texto de correção à redação do jornal, que, após avaliar, pode alterar o conteúdo da matéria. Dessa forma, o atributo correção de erros recebe a classificação "média transparência", ou seja, nota 2 (dois).

Quanto ao atributo propriedade, ao acessar o link "Expediente", há a informação de que as Organizações Globo controlam o jornal, bem como os nomes do presidente e seus vice-presidentes. Dessa forma, o atributo 
propriedade recebe a classificação "transparência total", ou seja, nota 4 (quatro).

Com relação ao atributo interatividade, "O Globo" disponibiliza uma grande gama de ferramentas interativas, tais como: comentar notícias, corrigir notícias, enviar cartas ao editor, enviar artigos, blogs; sendo necessário o cadastramento do usuário, o que pode ser feito facilmente e sem ônus ao leitor. Dessa forma, o atributo interatividade recebe a classificação "boa transparência", ou seja, nota 3 (três), por não haver ações de estímulo à interação.

\subsection{Análise dos atributos do jornal eletrônico de "O Estado de São Paulo"}

A versão eletrônica do jornal "O Estado de São Paulo" disponibiliza informações referentes ao atributo correção de erros de forma esparsa. Para cada correção, apresenta-se o trecho da matéria original onde ocorreu o erro, o comentário do que estava errado e na seqüência o texto da notícia, na integra, devidamente corrigido. Dessa forma, atribuiu-se a esse atributo a classificação "média transparência", ou seja, nota 2 (dois).

Com relação ao atributo propriedade, acessando o link "Responsabilidade Corporativa", disponível na parte inferior ("rodapé") de todas as páginas do jornal, encontra-se disponível a informação bem detalhada da estrutura societária atual do Grupo Estado, tendo a Família Mesquita no controle das operações. Dessa forma, para 0 item propriedade atribui-se a classificação "boa transparência", ou seja, nota 3 (três).

Para o atributo política de emprego, no rodapé da página principal há o link "responsabilidade corporativa", que dá acesso ao relatório publicado em 2006. Nesse relatório consta que o Grupo Estado prima em: "Oferecer ambiente de trabalho seguro e clima favorável ao exercício profissional, zelar pela conduta ética no tratamento aos colaboradores, aprimorar a gestão de recursos humanos e reconhecer o talento dos profissionais, com oportunidades de crescimento". Também é informado que, em 2007, seria lançado um Código de Conduta Ética, que pautaria as atitudes do corpo de funcionários das empresas do Grupo. Pesquisando o sítio em janeiro de 2008, o prometido Código de Conduta Ética não foi encontrado. Apesar de indicar intenções gerenciais que objetivem melhor direcionamento para política de emprego, não há um texto central que possa ser considerado um código de ética, nem um texto que oriente os colaboradores no momento da ocorrência de conflitos de interesse. Dessa forma, atribui-se a classificação "transparência inexistente", ou seja, nota 0 (zero), ao aspecto política de emprego.

Com referencia ao atributo política editorial, acessando na página principal o link "Responsabilidade Corporativa", apresenta-se a informação da criação da Diretoria de Conteúdo e, também, do Comitê de Auditoria e o Grupo de Avaliação Editorial (GAE). O GAE é formado por jornalistas do grupo e de fora, é acompanhado por Recursos Humanos, e analisa os 
veículos e a observância aos "Princípios Editoriais, Normas Éticas e de Qualidade". Apesar da descrição das atitudes gerenciais do jornal relativas a uma eficaz política editorial, encontra-se nessas seções apenas partes de textos diretamente associados à política editorial; não há uma local onde se encontre uma redação centralizada e precisa sobre a política editorial vigente. Dessa forma, atribui-se a classificação "pouca transparência" para o tópico política editorial, ou seja, nota 1 (um).

Acerca da interatividade, o jornal disponibiliza ferramentas de comentários que exigem o cadastramento prévio do leitor que irá comentar a notícia. A partir do cadastramento, os leitores são informados das condições de uso do portal Internet do Grupo Estado e se comprometem a respeitar o Código de Conduta On-line. A publicação dos comentários ocorre instantaneamente, sem análises prévias, porém sujeitas a posterior censura, caso deponha contra o Código de Conduta On-line. Dessa forma, atribuiu-se a classificação de "boa transparência" a este tópico, ou seja, nota 3 (três).

\subsection{Análise dos atributos do jornal eletrônico do "Extra"}

A versão eletrônica do jornal "Extra" não disponibiliza informações referentes aos atributos: correção de erros, política de emprego e política editorial. Assim, atribuiu-se a eles a classificação "transparência inexistente", ou seja, nota 0 (zero). Quanto ao atributo propriedade, ao acessar o link "Expediente", há a informação de que as Organizações Globo controlam o jornal, bem como os nomes do presidente e seus vicepresidentes. Dessa forma, o atributo propriedade recebe a classificação "transparência total", ou seja, nota 4 (quatro). Para o atributo interatividade, destaca-se a facilidade para o envio de mensagens ao editor, recebendo, portanto, a classificação "pouca transparência", ou seja, nota 1 (um).

\subsection{Análise dos atributos do jornal eletrônico do "Zero Hora"}

A versão eletrônica do jornal "Zero Hora" não disponibiliza informações referentes aos atributos: correção de erros, política de emprego e política editorial, assim, atribuiu-se a eles a classificação "transparência inexistente", ou seja, nota 0 (zero). Quanto ao atributo propriedade, em todas as telas do jornal é informado ao leitor ser esta uma empresa pertencente ao Grupo RBS, e, ao clicar no nome ou logo do grupo, abre-se uma janela que conta um pouco da história do grupo sem, no entanto, explicitar os nomes dos proprietários. Dessa forma, atribui-se a classificação "média transparência", ou seja, nota 2 (dois). Para o atributo interatividade, observou-se que, na parte inferior de todas as telas (no "rodapé" das páginas), há a opção "fale conosco", que permite o envio de mensagens ao editor. Para algumas notícias existe a facilidade do link "comente esta matéria", que solicita, inclusive, o fornecimento de 
um número de telefone do comentarista. As mensagens enviadas não são prontamente disponibilizadas, o que permite deduzir haver uma "filtragem" prévia do texto enviado. Para essas notícias com facilidades de "comentários", é possível ler os comentários enviados por outros usuários. Dessa forma, para interatividade atribui-se a classificação "pouca transparência", ou seja, nota 1 (um).

\subsection{Análise dos atributos do jornal eletrônico do "Diário Gaúcho"}

A versão eletrônica do jornal "Diário Gaúcho" não disponibiliza informações referentes aos atributos: correção de erros, política de emprego e política editorial; assim, atribuiu-se a eles a classificação "transparência inexistente", ou seja, nota 0 (zero). Quanto ao atributo propriedade, em todas as telas do jornal é informado ao leitor ser esta uma empresa pertencente ao Grupo RBS, e, ao clicar no nome ou logo do grupo, abre-se uma janela que conta um pouco da história do grupo sem, no entanto, explicitar os nomes dos proprietários. Dessa forma, atribuiuse a classificação "média transparência", ou seja, nota 2 (dois). Para o atributo interatividade, destaca-se a facilidade para envio de mensagem ao editor, recebendo, portanto, a classificação "pouca transparência", ou seja, nota 1 (um).

\subsection{Análise dos atributos do jornal eletrônico do "Correio do Povo"}

A versão eletrônica do jornal "Correio do Povo" não disponibiliza informações referentes aos atributos: correção de erros, propriedade, política de emprego e política editorial; assim, atribuiu-se a eles a classificação "transparência inexistente", ou seja, nota 0 (zero). Quanto ao atributo interatividade, a única facilidade disponível é a de envio de mensagem ao editor, recebendo, portanto, a classificação "pouca transparência", ou seja, nota 1 (um).

\subsection{Análise dos atributos do jornal eletrônico do "Super Notícia"}

A versão eletrônica do jornal "Super Notícia" não disponibiliza informações referentes aos atributos: correção de erros, propriedade, política de emprego e política editorial; assim, atribuiu-se a eles a classificação "transparência inexistente", ou seja, nota 0 (zero). Quanto ao atributo interatividade, a única facilidade disponível é a de envio de mensagem ao editor, recebendo, portanto, a classificação "pouca transparência", ou seja, nota 1 (um). 


\subsection{Análise dos atributos do jornal eletrônico de "O Dia"}

A versão eletrônica do jornal "O Dia" não disponibiliza informações referentes aos atributos: correção de erros, propriedade, política de emprego e política editorial; assim, atribuiu-se a eles a classificação "transparência inexistente", ou seja, nota 0 (zero). Quanto ao atributo interatividade, destaca-se a presença do link "fale conosco"; porém, esse se encontra inoperante ("link quebrado"), recebendo, portanto, a mesma classificação que os demais atributos: "transparência inexistente".

\section{Reflexões sobre o uso de dimensões para averiguação da qualidade da informação}

Realizadas as duas primeiras fases da pesquisa - (a) compreensão dos critérios adotados pelo ICMPA para avaliar a confiabilidade de 25 importantes sítios de notícias e (b) a replicação da pesquisa para o contexto brasileiro -, os pesquisadores analisaram 0 experimento realizado e os resultados alcançados, com o objetivo de compreender e interpretar a realidade dentro do contexto estudado. Nesse método de pesquisa, o fenomenológico, é importante destacar que a realidade não é única, porem válida cientificamente por caracterizar a compreensão de uma realidade dentro de um contexto, que pode vir a subsidiar e corroborar com análises futuras (TRIVIÑOS, 1992).

As conclusões obtidas referenciam aspectos críticos para a gestão da qualidade da informação, dos quais o gestor do ambiente informacional deve ter discernimento e domínio. Os aspectos críticos identificados estão apresentados em dois grupos: (a) metainformações associadas à qualidade da informação e (b) processo para gestão da qualidade da informação.

\subsection{Metainformações associadas à análise da qualidade da informação}

Assim como a gestão de dados envolve o uso de metadados, a eficaz gestão do recurso informação envolve metadados e metainformações. Como exemplos de metadados, citam-se os elementos descritivos: "formato", que informa se o conteúdo do dado em questão é numérico, alfabético ou alfa-numérico; "tamanho", que informa a quantidade de caracteres possíveis. Assim, em uma situação prática, um analista de negócios que compreende que o dado "nome" de determinada entidade deve contemplar tanto caracteres alfabéticos quanto numéricos, e que deve ter tamanho máximo de 30 caracteres, definirá os metadados referentes ao dado "nome" da seguinte forma: "elemento descritivo 'formato' igual à alfa-numérico" e "elemento descritivo 'tamanho' igual a 30 caracteres". Como exemplo de aplicação prática de metadados, cita-se o padrão Dublin Core (DC) para descrição de sítios da Internet, composto por 18 elementos descritivos: título; autor ou criador; palavras-chave; 
categoria; descrição; publicador; colaborador; data; tipo; formato; acesso; identificador de recurso; fonte; idioma; relação; cobertura; direito autoral; contato (SOUZA, VENDRUSCULO e MELO, 2000).

Os metadados são os dados que descrevem (elementos descritivos) outros dados, como o próprio nome sugere e stão facilmente disponíveis aos interessados. "É dado", ou seja, fornecido, disponibilizado ou de fácil percepção e consenso. Para descrição dos sítios da Internet, o elemento descritivo "idioma" é dado, basta averiguar o idioma utilizado nos textos do sítio. Normalmente, para a atividade de levantamento de dado, basta uma simples observação ou interação com a entidade, por exemplo, um questionamento: "Qual o seu nome?". A averiguação da qualidade da informação é uma atividade que requer ir além da observação de dados; há a necessidade da análise destes. Por essa razão, utiliza-se a denominação "análise da qualidade da informação" e não "levantamento da qualidade da informação".

O problema associado à análise da qualidade da informação - por exemplo, de um relatório ou parecer técnico organizacional, quando se deseja saber se deve ou não ser utilizado para um processo de tomada de decisão - é que ela não se restringe a atividades triviais de observação ou levantamento de dados. A atividade de análise da qualidade da informação prossegue além da primeira etapa de levantamento de dados, que subsidia a segunda e mais complexa atividade: a apuração da qualidade da informação segundo regras pré-estabelecidas. Desta forma, identifica-se que a qualidade da informação é expressa por intermédio de informações, e não por dados. Utilizando-se do exemplo da pesquisa realizada, quando se informa que determinado jornal virtual apresenta "média transparência", deve haver consenso entre o grupo de gestores, usuários e interessados na informação do que seja "transparência", assim como da valoração atribuída: "médio nível". A informação organizacional de qualidade está associada a várias outras informações que descrevem sua qualidade, ou seja, informações referentes às diversas dimensões da qualidade. Assim, tem-se que o resultado da análise da dimensão de qualidade da informação é a geração de um conjunto de metainformações, ou seja, informações referentes a outras informações.

A averiguação da qualidade da informação é uma atividade analítica, portanto complexa, que abrange atividades taxionômicas e ontológicas. Entre os desafios ontológicos, encontra-se a própria dificuldade de definição das dimensões da qualidade da informação, conforme descrito na seção um, pois ainda não há consenso na literatura sobre definições teóricas e operacionais referentes à qualidade da informação. A título de exemplo, a própria definição de nomes das dimensões da qualidade já configura um grande desafio, conforme se pode observar nas duas situações descritas no QUAD. 2, ambas envolvendo situações de falsos sinônimos.

Além da escolha do nome das dimensões a serem analisadas na gestão da qualidade das informações, os gestores da informação devem preocupar-se com: a definição das dimensões e dos atributos utilizados 
para análise de cada dimensão, e dos aspectos ou regras a serem consideradas para análise de cada atributo. $\mathrm{Na}$ pesquisa realizada, utilizaram-se cinco atributos para mensurar a dimensão confiabilidade da fonte: correção de erros; propriedade; política de emprego; política editorial e interatividade. Para cada atributo consideraram-se vários aspectos. Por exemplo, para o atributo "propriedade", analisaram-se aspectos associados à qualidade da redação que a declara: facilidade de acesso, ou seja, quantidade de cliques de mouse para se chegar à informação; e consistência, ou seja, se é clara e objetiva.

O pleno entendimento da tríade "dimensão - atributo - aspecto" é fundamental ao gestor da informação. A pesquisa realizada discutiu e exemplificou, com um caso prático, cada um desses três elementos essenciais à medição da qualidade da informação. Assim, nessa primeira reflexão, cabe destacar ser muito importante ao gestor da informação compreender o que seja: dimensões para análise da informação, atributos que caracterizam cada dimensão e aspectos a serem analisados para cada atributo. A estruturação dos elementos que compõem a tríade, associada aos valores ou notas atribuídas para cada associação possível de ser encontrada, caracteriza a constituição das regras para análise das dimensões da qualidade da informação. A definição dessas estruturas e das associações entre elas configuram um exercício taxionômico.

\title{
QUADRO 2 - Exemplos de dificuldades na definição de nomes para dimensões da qualidade
}

\begin{abstract}
Dimensão escopo/abrangência da informação
Muitos gestores da informação e pesquisadores utilizam o termo completeza ou coesão para designar a dimensão que trata da análise do tamanho da informação, para analisar se a informação não é sucinta/breve ou longa/extensa demais. Esses nomes podem acarretar vieses indesejáveis no processo de gestão da qualidade da informação corporativa. O uso do termo completeza para nomeação de uma dimensão direciona a atenção do gestor e dos usuários da informação para falta ou limitação da extensão da informação, não direcionando a análise do gestor para outro importante aspecto, tão problemático e corriqueiro quanto a falta de informação: o excesso da informação. O uso do termo coesão provoca o viés inverso, direcionando a atenção do gestor e usuários da informação para o não exagero em termos de abrangência, dando pouca atenção ao problema da falta ou da sua síntese excessiva. Dessa forma, para essa dimensão, ao invés dos nomes completeza ou coesão, deve se empregar os termos abrangência ou escopo da informação, por serem mais gerais, e conduzirem os interessados a pensarem nas duas situações indesejáveis: "o excesso de" e "a falta de".

Dimensão ineditismo/raridade da informação

A dimensão ineditismo aborda o nível de raridade de determinada informação, considerando-se o seu nível de exposição, ou seja, o quanto ela já foi divulgada. Alguns gestores da informação e pesquisadores utilizam o termo novidade como sinônimo de ineditismo/raridade, o que configura uma grande confusão. Nessa situação não se trata de restringir parte da análise do aspecto central da dimensão pesquisada, mas de tratar igualmente, de juntar, duas dimensões distintas. $O$ termo novidade refere-se ao período de tempo decorrido entre sua geração e o tempo que ocorre a análise. Uma informação pode ser bastante recente/nova, porém, já amplamente divulgada, enquanto outra, existente há séculos, pode ter sido tratada com alta restrição e apresentar um alto índice de ineditismo/raridade, apesar de sua idade avançada.
\end{abstract}

Fonte: Elaborado pelos autores. 


\subsection{0 processo de gestão da informação}

$\mathrm{Na}$ pesquisa realizada pelo ICMPA, definiu-se a qualidade de transparência como principal critério para análise da dimensão confiabilidade do jornal eletrônico. Todos os atributos foram definidos a partir dela: transparência sobre a política editorial; sobre a interação com os leitores; sobre a política de emprego; sobre o tratamento de erros cometidos. Essa definição fundamentou-se no conhecimento dos pesquisadores do ICMPA sobre o segmento de negócio, considerando que os meios de comunicação são o objeto central das pesquisas do grupo. Analogamente, a pesquisa replicada para o contexto Brasil, envolveu, nas atividades de definição dos atributos e de seus aspectos para análise, profissionais com amplo domínio no âmbito da informação. Estes profissionais que definem atributos e aspectos para análise da qualidade normalmente possuem experiência significativa na área de negócio, no processo de negócio ou em outro âmbito de interesse associado diretamente à informação que se queira analisar. Para esses profissionais, que auxiliam a definir as regras de avaliação da qualidade da informação, utiliza-se o termo usuários-chave do ambiente informacional.

Considerando-se a grande diversidade de informações utilizadas no contexto da organização, pode-se afirmar que diversos usuários-chave do ambiente informacional da organização estarão envolvidos, trabalhando conjuntamente com o responsável pela gestão da informação na definição de atributos e de aspectos a serem analisados para cada informação identificada como importante ao negócio. Ao gestor da informação cabe: a definição das dimensões, o desenvolvimento da cultura organizacional da importância de se trabalhar com informação de qualidade, além do estabelecimento dos meios e procedimentos para que os usuários-chave do ambiente informacional possam melhor definir os atributos e os aspectos necessários para análise de cada informação relevante à organização.

Além dos usuários-chave, que requerem uma nova informação, a discussão sobre os atributos para análise de uma determinada dimensão da qualidade da informação deve considerar o envolvimento de diversos outros atores: leitores intensivos da informação, responsáveis pela geração de informações de mesma natureza, vendedores ou comerciantes da informação, pesquisadores ou cientistas da informação, profissionais que atuem no mesmo segmento de negócio, entre outros. Retornando à experiência da análise da dimensão confiabilidade para fonte jornais eletrônicos brasileiros, ao apresentar os atributos e os aspectos considerados pela equipe do ICMPA para alguns atores que pudessem contribuir com as regras de avaliação da dimensão confiabilidade das fontes (jornal eletrônico) brasileiras, diversas sugestões e recomendações foram apresentadas. A título de exemplo, um dos atores consultados - um editor de jornal - sugeriu uma sexta dimensão de análise: "principais 
anunciantes"; o atributo sugerido está descrito no Quadro 3. Ressalta-se que, embora o atributo não tenha sido utilizado na análise de confiabilidade dos jornais eletrônicos brasileiros, foi considerado pertinente pelos pesquisadores; a sua não utilização se deve apenas à coerência entre os atributos e aspectos considerados entre as duas pesquisas. Conforme destacado anteriormente, o objetivo principal da pesquisa não foi identificar o nível de confiabilidade dos jornais eletrônicos em si, mas os procedimentos associados à identificação e definição de atributos e aspectos a serem considerados na análise.

\section{QUADRO 3 - Descrição do atributo sugerido "maiores anunciantes" e os} aspectos a serem considerados na sua análise

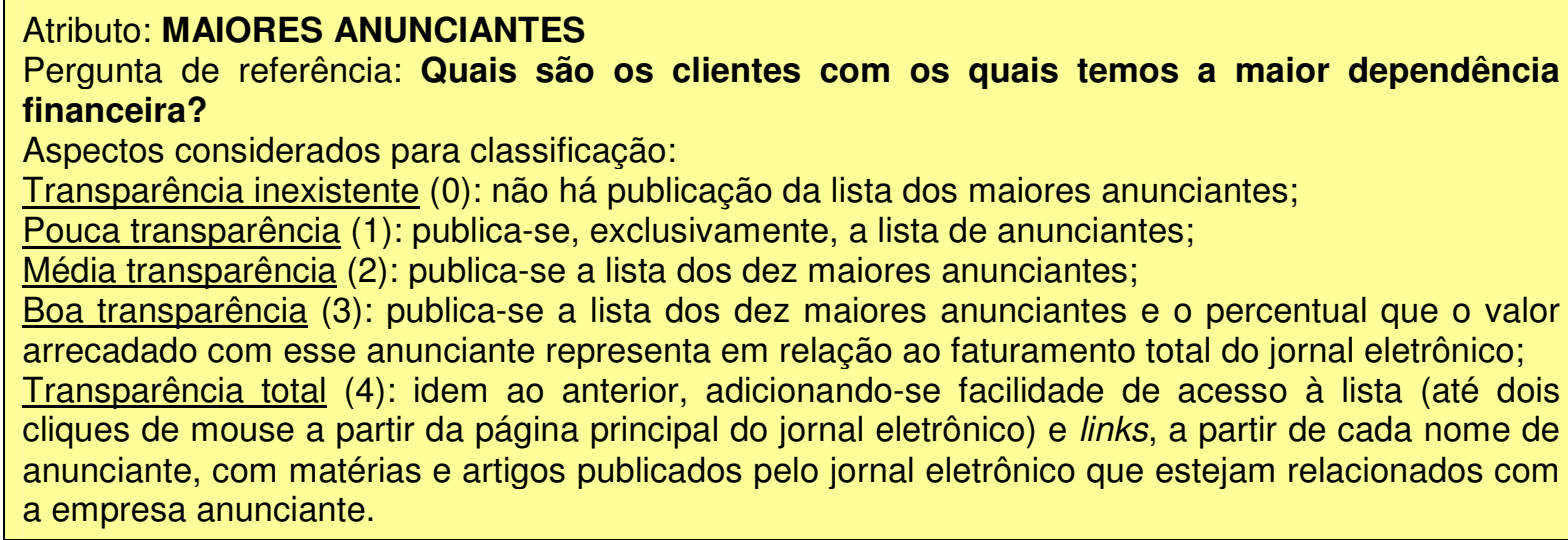

FONTE: Elaborado pelos autores.

Destas observações, análises e experimentos, depreende-se que o gestor do ambiente informacional deverá articular-se junto a uma gama bastante ampla de usuários-chave do ambiente informacional e atores para definição de atributos e de seus aspectos relacionados à mensuração de cada dimensão da qualidade das informações identificadas como relevantes à organização. Exemplificando a diversidade de atores, considere, por exemplo, a análise da qualidade da dimensão acurácia da informação. Poder-se-ia considerar o envolvimento de um estatístico para discutir os aspectos ou critérios de análise para o atributo "método para determinação do nível de acurácia da informação". Quanto ao contexto da informação analisada, retoma-se o exemplo da análise realizada para os jornais eletrônicos; seria então o caso de envolver editores e responsáveis por áreas de gestão de pessoas, que atuem nesse segmento de negócio, para discutir, respectivamente, os atributos e seus aspectos de análise relativos à "política editorial" e à "política de emprego".

O Esquema 1 descreve as atividades envoltas no processo de gestão da qualidade do recurso informação, declarando, também, a freqüência com que essas ocorrem e seus responsáveis. As atividades são classificadas em três diferentes níveis: (a) estratégico, responsável por definir o que é informação de qualidade para a organização; (b) gerencial, responsável definir atributos e aspectos para análise da qualidade de uma nova informação; ou (c) operacional, responsável por apurar os aspectos 
para cada nova instância da informação que está sendo criada ou atualizada; ou simplesmente pela atividade de leitura e interpretação dos aspectos relacionados à qualidade de uma instância da informação em questão, a fim de decidir pelo seu uso, ou não, como instrumento de apoio a uma tomada de decisão organizacional.

O grupo de pesquisa do ICMPA declarou, nas conclusões da pesquisa, que não ocorre de imediato a associação entre aumento dos níveis de transparência com o aumento do nível de confiabilidade dos leitores em relação ao jornal (INTERNATIONAL..., 2007). Há a necessidade de se educar os leitores da informação com relação à importância de cada atributo para qualidade da informação que se lê, ou seja, auxiliá-los a entenderem a importância da transparência para cada um dos atributos. O leitor deve ter ciência do que pode acarretar a nãotransparência do jornal com relação aos atributos; de como isso pode prejudicar os leitores em termos de ausência da informação, ou mesmo da presença da não-informação, que é a informação de má qualidade (incorreta, imprecisa, desatualizada e demais características indesejáveis à informação). Destes fatos observados e das análises realizadas, depreende-se que as organizações terão que desenvolver a cultura da qualidade da informação, explicitando as dimensões da informação de qualidade, seus atributos e aspectos de análise, discutindo seus reflexos na qualidade percebida pelo leitor final.

Como já citado, a tradição das organizações é a de gerir os recursos de tecnologia da informação, e não a informação em si. Os aspectos relacionados à qualidade da informação são pouco praticados nas organizações e, consequentemente, há pouca experiência e discernimento a respeito. Assim, as ações relacionadas à qualidade da informação devem incluir a capacitação e a transferência de conhecimento com relação ao que deve ser considerado em termos de gestão de qualidade da informação e sua importância para a comunidade leitora. As ações de divulgação e treinamento se tornam ainda mais importantes quando a informação é o produto final da organização, como é o caso dos jornais eletrônicos pesquisados; ou quando ela é parte integrante ou fortemente associada ao produto ou serviço principal entregue pela organização. Nesses casos, além de desenvolver os conceitos junto ao público de leitores internos da informação, há de se desenvolver também os clientes, fornecedores, governo e demais leitores de informação externos à organização, de forma a evidenciar o valor e a importância das ações de gestão da qualidade da informação desenvolvidas pela organização em termos de melhor qualidade da informação entregue. 


\begin{tabular}{|c|c|c|}
\hline $\begin{array}{l}\text { ATIVIDADES } \\
\text { (O que fazer?) }\end{array}$ & $\begin{array}{l}\text { FREQUÊNCIA } \\
\text { (Quando?) }\end{array}$ & $\begin{array}{c}\text { RESPONSABILIDADE } \\
\text { (Quem?) }\end{array}$ \\
\hline $\begin{array}{c}\text { definir } \\
\text { dimensões }\end{array}$ & $\begin{array}{l}\text { RARAMENTE } \\
\text { Quando da definição e revisões } \\
\text { da estratégia para análise da } \\
\text { qualidade do recurso informação }\end{array}$ & $\begin{array}{l}\text { COMITÊ RESPONSÁVEL } \\
\text { PELA ESTRATÉGIA } \\
\text { do recurso informação }\end{array}$ \\
\hline $\begin{array}{c}\text { definir } \\
\text { atributos }\end{array}$ & \multirow{2}{*}{$\begin{array}{l}\text { PONTUALMENTE } \\
\text { Na definição de cada nova } \\
\text { informação organizacional } \\
\text { identificada como necessária } \\
\text { PONTUALMENTE } \\
\text { Na definição de cada nova } \\
\text { informação organizacional } \\
\text { identificada como necessária }\end{array}$} & \multirow[t]{2}{*}{$\begin{array}{l}\text { USUÁRIO-CHAVE } \\
\text { solicitante e responsável } \\
\text { pela nova informação } \\
\text { organizacional }\end{array}$} \\
\hline $\begin{array}{l}\text { definir } \\
\text { aspectos }\end{array}$ & & \\
\hline Operacionais: & \multirow{2}{*}{$\begin{array}{l}\text { FREQUENTEMENTE } \\
\text { A cada geração de uma nova } \\
\text { instância da informação, } \\
\text { conforme a periodicidade definida } \\
\text { o ato da sua definição (anual, } \\
\text { semestral, semanal, diária, ...) } \\
\text { FREQUENTEMENTE } \\
\text { A cada utilização da informação, } \\
\text { a fim de averiguar se o nível de } \\
\text { qualidade é apropriado ao risco } \\
\text { envolto na decisão em questão }\end{array}$} & \multirow[t]{2}{*}{$\begin{array}{l}\text { TRABALHADOR DA } \\
\text { INFORMAÇÃO responsável } \\
\text { pela geração de cada instância } \\
\text { da informação }\end{array}$} \\
\hline $\begin{array}{l}\text { analisar status de } \\
\text { cada dimensão }\end{array}$ & & \\
\hline
\end{tabular}

Esquema 1 - Processo de gestão da qualidade para o recurso informação Fonte: Elaborado pelos autores.

\section{Considerações finais}

Conclui-se, a partir do contexto pesquisado, que a introdução do importante conceito de metainformação para gestão da qualidade da informação exigirá muito esforço e dedicação das organizações e dos acadêmicos. Entre as razões destacam-se:

- fundamentação teórica ainda incipiente, considerando que não há consenso pleno sobre o conjunto de dimensões da qualidade da informação;

- dificuldade de disponibilizar modelos genéricos (templates) que possam facilitar a criação de regras para avaliação de dimensões da qualidade da informação, considerando que a definição dos atributos e de seus aspectos de análise 
apresentam forte dependência de características distintivas de cada empresa: segmento de negócio, processos de negócios, estratégia e outras especificidades associadas à organização ou à informação específica;

- demanda atividade de análise e não apenas de observação de dados, o que exigirá mudança de comportamento por parte dos indivíduos que atuam no "ambiente informacional", bem como da cultura da organização; ambos fortemente atrelados à cultura do processamento de dados.

A partir do contexto estudado, também se pode inferir a respeito do processo de gestão da qualidade da informação:

- o gestor do processo deverá atuar e interagir junto a muitos usuários-chave do ambiente informacional e atores, considerando as características das atividades de definição de atributos e de seus aspectos relacionados à mensuração de cada dimensão da qualidade da informação;

- no escopo dos trabalhos deve estar incluso o desenvolvimento da cultura da qualidade da informação, explicitando as dimensões da informação de qualidade, seus atributos e aspectos de análise, discutindo seus reflexos na qualidade da informação junto aos leitores finais e demais interessados;

- requererá maior atenção e dedicação da organização ao recurso informação, obtido a partir do redirecionamento de esforços da organização nos recursos de tecnologia da informação.

Quanto ao experimento realizado, cabe destacar que, ao invés de se trabalhar com atributos e seus aspectos de análise, poder-se-ia, simplesmente, adotar, por exemplo, uma pesquisa junto aos leitores, identificando os jornais em que eles mais confiam. Mas esse método estaria carregado de subjetividade. Os pesquisadores trabalharam no sentido de encontrar atributos específicos, relacionados à qualidade das fontes pesquisadas (jornais eletrônicos), que fossem possíveis de serem analisados e mensurados, e que pudessem atender aos objetivos da pesquisa em conformidade com o rigor requerido à pesquisa científica.

$O$ resultado das análises das mídias brasileiras é coerente com os resultados obtidos na pesquisa em âmbito global realizado pelo ICMPA, junto aos 25 mais importantes jornais eletrônicos. A mídia brasileira mais bem avaliada, "Folha de São Paulo", dentro do contexto global de transparência gerado pelo ICMPA, estaria na décima posição com a mesma pontuação que o "Washington Post", ambos com avaliação igual a 2,4 (dois inteiros e quatro décimos), ou seja, "média transparência". As avaliações obtidas pelas duas mídias nos cinco atributos são muito próximas. Comparando as duas pesquisas, observam-se os mesmos padrões de classificação dos atributos relacionados à confiabilidade; ou seja, as dificuldades dos principais jornais brasileiros com respeito à 
transparência são as mesmas das dos grandes jornais internacionais. $\mathrm{Na}$ pesquisa do ICMPA, apenas 13 (treze) dos 25 (vinte e cinco) jornais analisados receberam avaliação maior ou igual a 2 (dois), ou seja, compreendidos como mídias de "média transparência".

A pouca transparência apurada pela pesquisa para as versões eletrônicas dos jornais, tanto internacionais quanto nacionais, confirma as evidências da falta de cultura organizacional com relação à eficaz gestão da qualidade do recurso informação. Era de se esperar uma maior atenção por parte dessas organizações, por ser um segmento de negócio que tem a informação como produto final e, portanto, deveria privilegiar a gestão da qualidade da informação. O que se constatou foi que essas empresas de mídia não exercitam a eficaz gestão do recurso informação, pelo menos no que tange à dimensão confiabilidade da fonte da informação.

Com a análise da dimensão confiabilidade, evidenciou-se que os jornais eletrônicos deveriam, como forma de respeito aos seus leitores: publicar os erros cometidos, admiti-los e corrigi-los; deixar claro quem são seus proprietários, não os escondendo a partir da declaração de Sociedades Anônimas; publicar aos seus leitores e profissionais do mercado as políticas de emprego; pautar-se pela clareza da política editorial e estimular a interatividade produtiva e sadia que a democracia requer.

A constante observância das dimensões da qualidade da informação como critério para sua utilização por parte daqueles que necessitam de informação (última atividade do processo de gestão da qualidade da informação descrita no Esquema 1), implicaria na constituição de uma nova cultura informacional no contexto das organizações. Para que esse novo cenário se concretize, é necessário atender às carências organizacionais apontadas por Oleto (2006), de que existam referenciais que auxiliem usuários do ambiente informacional a terem a prática e "a experiência de pensar a informação a partir de sua qualidade" (ibid, p. 61). Para a superação dessas carências, são necessárias pesquisas relacionadas à discussão das dimensões da qualidade da informação e da forma de mensurá-las. Nesse contexto, evidencia-se a contribuição da presente pesquisa, pela discussão e exemplificação: (a) de uma das dimensões de qualidade da informação (a confiabilidade da fonte) e (b) dos conceitos, atividades e profissionais envolvidos no processo de gestão da qualidade da informação.

\section{Referências}

ASSOCIAÇÃO NACIONAL DE JORNAIS. Maiores Jornais do Brasil. Disponível em: <http://www.anj.org.br/a-industria-jornalistica/jornais-nobrasil/maiores-jornais-do-brasil>. Acesso em: 7 nov. 2007.

CARVALHO, J. R. et al. Meta-information about MARC: an XML framework for validation, explanation and help systems. Library Hi Tech, Bradford, v.22, n.2, p.131-137, 2004. 
DAVENPORT, T. H. Ecologia da Informação. São Paulo: Editora Futura, 2002.

GARVIN, D. A. Managing Quality. New York: The Free Press, 1988.

GIDDENS, A. As conseqüências da modernidade. São Paulo: Editora da Universidade Estadual Paulista, 1991.

GIL, A. C. Como elaborar projetos de pesquisa. São Paulo: Atlas, 1991.

HARRIS, R. Evaluating Internet research sources. Disponível em: <http://www.virtualsalt.com/evalu8it.htm>. Acesso em: 16 maio 2006.

HUANG, K.;LEE, Y. W.; WANG, R. Y. Quality Information and Knowledge. New York: Prentice-Hall, 1999.

INTERNATIONAL CENTER FOR MEDIA AND THE PUBLIC AGENDA. Openness \& Accountability: A Study of Transparency in Global Media Outlets, jun. 2007. Disponível em: <http://www.icmpa.umd.edu/pages/studies/transparency/main.html> Acesso em: 14 set. 2007.

LAKATOS, E. M.; MARCONI, M. A. Fundamentos de metodologia científica. São Paulo: Atlas, 1993.

OLETO, R. R. Percepção da qualidade da informação. Ciência da Informação, Brasília, v.35, n.1, p.57-62, jan./abr. 2006.

PAIM, I.; NEHMY, R. M. Q.; GUIMARÃES, C. G. Problematização do conceito "Qualidade" da Informação. Perspectivas em Ciência da Informação, Belo Horizonte, v.1, n.1, p. 111-119, jan./jun. 1996.

RANFT, A.; LORD, M. Acquiring new technologies and capabilities: a grounded model of acquisition implementation. Organization science, v.13, n.4, p.420-441, 2002.

RIEH, S. Y.; DANIELSON, D. Credibility: A multidisciplinary framework. In: Annual Review of Information Science and Technology (ARIST). Medford: Information Today, 2007. cap. 7, p. 307-364.

RODRIGUES, C. M. Políticas editoriais: processo de produção e difusão do conhecimento novo. In: ENCONTRO IBERO-AMERICANO DE EDITORES DE REVISTAS DE COMUNICAÇÃO, 1., 1986, São Paulo. Anais... São Paulo: [s.n.], 1986.

ROSINHA, R. C. Política editorial: aspectos a considerar. Revista de Biblioteconomia de Brasília, Brasília, v.17, n.2, p. 249-258, jul./dez. 1989.

SALMELA, H. From information systems quality to sustainable business quality. Information and Software Technology, v.39, n. 12, p.819-25, 1997.

SCHWUCHOW, W. Problems in evaluating the quality of information services. In: WORMELL, I. (Org.). Information quality: definitions and dimensions. London: Taylor Graham, 1990. p.69-72. 
SLATER, M. D.; ROUNER, D. How message evaluation and source attributes may influence credibility assessment and belief change. Journalism and Mass Communication Quarterly, Columbia, v.73, n.4, p. 974-991, Winter. 1996.

SOUZA, M. I. F.; VENDRUSCULO, L. G.; MELO, G. C. Metadados para a descrição de recursos de informação eletrônica: utilização do padrão Dublin Core. Ciência da Informação, Brasília, v.29, n.1, p.93-102, jan./abr. 2000.

SVEIBY, K. A knowledge-based theory of the firm to guide in strategy formulation. Journal of Intellectual Capital, Bradford, v.2, n.4, p.344-358, 2001.

TSENG, S.; FOGG, B. J. Credibility and computing technology. Communications of the ACM, New York, v. 42, n.5, p. 39-44, May 1999.

TOZER, G. Metadata Management for Information Control and Business Success. Norwood (MA): Artech House, 1999.

TRIVIÑOS, A. N. S. Introdução à pesquisa em ciências sociais: a pesquisa qualitativa em educação. São Paulo: Atlas, 1992.

VEDDER, A.; WACHBROIT, R. Reliability of information on the Internet: Some distinctions. Ethics and Information Technology, Dordrecht, v.5, n.4, p. 211-215, 2003. 